\title{
Analysis of the linkage between viral, bacterial, and protozoal infections and the level of reproductive losses in dairy herds in the Ural region
}

\author{
O.V. Sokolova ${ }^{1, *}, E . N$. Shilova ${ }^{1}, I . A$. Shkuratova ${ }^{1}$, and M.V. Ryaposova ${ }^{1}$ \\ ${ }^{1}$ Federal State Budgetary Institution "Ural Federal Agrarian Scientific Research Center of the Ural \\ Branch of the Russian Academy of Sciences", 620142 Yekaterinburg, Russia
}

\begin{abstract}
The analysis of the linkage between infection of dairy herds in the Ural region with BVDV, BHV-1, C. abortus and N. caninum with indices of reproductive function and reproductive losses was performed. The results of studies of 1453 samples of biological material by Elisa, PCR and Real-Time PCR were taken into account. The level of BVDV infection in animals of various physiological groups in the examined farms ranged from 15.6 to $66.7 \%$, and the seroprevalence of the BHV-1 field strain was $31.8 \%$. The amount of seroprevalent to C. abortus animals in dairy herds was $55.1 \%$, to $\mathrm{N}$. caninum- $43.3 \%$. The lowest rates of fertilization were found in farms with simultaneous circulation of chlamydia and neosporosis pathogens and in mono-chlamydia infection. In these same herds, there was a longer post-partum interval. The highest mean rate of abortions in cows and heifers was in farms with N. caninum circulation, as well as in mixed infections, with increased action of infectious factors. In the analysis of viral infections, it was established that the highest level of perinatal losses was seen in the presence of BVDV.
\end{abstract}

\section{Introduction}

Pathogens of viral, bacterial and protozoal infections in cattle have a negative effect on the reproductive function of animals and may lead to reproductive losses, including BHV-1, BVDV, C. abortus, N. caninum [1-5]. Diseases often have a long-lasting chronic course, causing reproductive disorders and abortions in animals in epidemiologically unfavorable herds [6-9].

\section{Materials and methods}

We have investigated the relationship between the circulation of various infections in dairy cattle herds and indicators of reproductive function, the rate of abortions, and still birth. In

\footnotetext{
${ }^{*}$ Corresponding author: nauka_sokolova@mail.ru
} 
2015-2019, 1,453 samples of biological material from cows from more than 40 farms in the Ural region of Russia were studied. Bovine viral diarrhea virus antigens were identified in the ELISA using a kit "Bovine Viral Diarrhoea Virus (BVDV) Antigen Test Kit/Serum Plus», antibodies to the antigen $\mathrm{gE}$ of the virus of infectious rhinotracheitis of cattle using a test kit of "IBR gE Blocking Ab Test", antibodies to C. abortus using the kit "Chlamydiosis Total Ab Test", antibodies to N. caninum using the kit "Neospora X2 Ab Test" (IDEXX Laboratories, Inc, USA). The ELISA results were recorded on the SUNRISE reader (Tecan, Austria). Isolation of the BVDV pathogen from biomaterials was conducted on the MDBK cell-line incubated in an Igla (MEM) medium with $10 \%$ of the fetal serum of cattle. The results of the study were considered using an Axio Observer microscope (Zeiss, Germany). Identification of the isolated pathogen was performed by solid-phase ELISA using a kit "Bovine Viral Diarrhoea Virus" (BVDV) Isolation of pathogen DNA from biological material and PCR was conducted in conformance with the manufacturer's instructions for the use of test systems. In this work, we utilized a set of reagents for DNA isolation " Diatom DNA Prep 200 "(IsoGen OOO, Moscow), a set for defining the type of speciesspecific bovine chlamydia GenPak DNA PCR tect for amplifying the DNA of C. pecorum, C. abortus, Bovine herpes virus / type 1 (IsoGen OOO, Moscow), and sets for defining the bovine diarrhea virus (InterLabServis OOO, Moscow). To conduct amplification, the Applicede thermal cycler (Singapore) was used. The studies were performed in an electrophoretic version using agarose gel and Mini-Sub Cell GT (Bio-Rad, USA) with visualization under ultraviolet radiation in a CHEMIDOC XRS+ camera with interpretation of the results using gel documentation Gel Doc XR+ (Bio-Rad, USA). Investigations to determine the DNA of the agent of bovine viral diarrhea were conducted by polymerase chain reaction with real-time hybridization-fluorescence detection using the Rotor-Gene 3000 amplifier (Corbett Life Science, Australia). Statistical data processing was carried out using MS Excel 2007 and MS Excel 2013 analysis packages. The significance of differences in statistical estimates was defined using the Student $-\mathrm{t}$ criterion (the significance was deemed important at the level of $\mathrm{p}<0.05$ ).

\section{Results and discussion}

It was determined that $28.1 \%$ of the examined breeding and commercial dairy farms have dysfunctional epizootic situation for bovine viral diarrhea. The agent was found to have an antigen in $24.7 \%$ of samples from 9 farms. The infection rate of animals of different physiological groups in the examined farms ranged from 15.6 to $66.7 \%$.

The antigen of the agent was identified in $14.3 \%$ of clinical samples from aborted cows (placenta, fetal organs), which indicates infection of pregnant animals, virus circulation in dairy herds with the course of the infectious process in latent and subclinical form. The presence of bovine VD antigen in $22.8 \%$ of blood serum samples of newborn calves indicates transplacental transmission of the virus to the fetus before the formation of the immune system and the development of persistent infection against the background of immunological tolerance to the pathogen.

Virological research of field strains of BVDV received from clinical samples of infected animals showed on MDBK cell culture that a non-cytopathogenic virus biotype (NCP) is released in newborn calves. Both non-cytopathogenic (NCP) and cytopathogenic virus (CP) biotypes were equally found in biological material from post-abortion cows. 44 samples of biological material from cattle (organs of aborted fetuses, the fetal part of the placenta) were examined in PCR-RV). BVDV DNA was not identified.

The primary share of perinatal losses in BVDV was embryonic losses up to 45 days of pregnancy at the level of $17.1-20.2 \%$ and the birth of non-viable calves- $14.1 \%$, which is 3.5 times higher than the regional average. The total fertilization rate of cows in dairy herds 
with BVDV circulation in $2015-2019$ was $85.4 \pm 1.4 \%$ on average, and the fertilization from first AI was $48.0 \pm 1.8 \%$.

The effect of BHV-1 on the reproductive function of cows is mainly associated with infection of the corpus luteum tissues, which can affect the level of progesterone, playing an important role in the course of embryo implantation processes in early pregnancy [2]. According to the results of the studies, $31.8 \%$ of cows in dairy herds using labeled vaccines with the deletion of the gE gene were seropositive to BHV-1, which indicated the spread of non-vaccine strains of the virus. In polymerase chain reaction studies of 199 clinical samples (vaginal flushes, placenta, organs of aborted fetuses), the pathogen genome was found only in 1 sample $(0.5 \%)$ of biomaterial (vaginal swabs) obtained from a breeding farm. This suggests a predominantly latent course of infection, which is due, among other things, to the specific prevention of this disease, as well as to the unstable release of the virus because of its periodic replication under the influence of stress factors acting on the animal's body.

Total fertilization and fertilization from first $\mathrm{AI}$ in herds with BHV-1 circulation were on average lower than in farms with BVDV circulation and amounted to $74.8 \pm 1.8$ $\%(\mathrm{P} \leq 0.05)$ and $41.6 \pm 1.6 \%(\mathrm{P} \leq 0.01)$, respectively. The duration from post-partum interval was at the level of herds with bovine diarrhoea virus circulation. The rate of abortions in cows and heifers averaged $5.5 \%$, stillbirth rate- $7.8 \%$, and retirement of pregnant cows and heifers $-13.3 \%$. Therefore, the indicators of perinatal losses were lower than in bovine viral diarrhea, but they were $1.6-2.7$ times higher than the local average. Yet, the decline in indices reflecting the level of fertilization of cows was more pronounced.

Infections associated with BVDV and BHV-1 demonstrated an even more pronounced decrease in reproductive function. In herds with simultaneous circulation of BVDV and BHV-1, the total fertilization rate of cows was $80.1 \pm 3.1 \%(\mathrm{P} \leq 0.05)$, and the fertilization from the first AI was $42.9 \pm 2.3 \%$. The duration from birth to productive insemination was longer than in herds with mono - viral infection circulation and averaged 142.7 \pm 6.7 days $(\mathrm{P} \leq 0.01)$. Mean abortion rates were also higher at $6.9 \%(\mathrm{P} \leq 0.05)$, and the stillbirth rate was lower than with BVDV mono - infection, but higher than with BHV-1 - 13.8\% $(\mathrm{P} \leq 0.05)$ (Figure 1). 


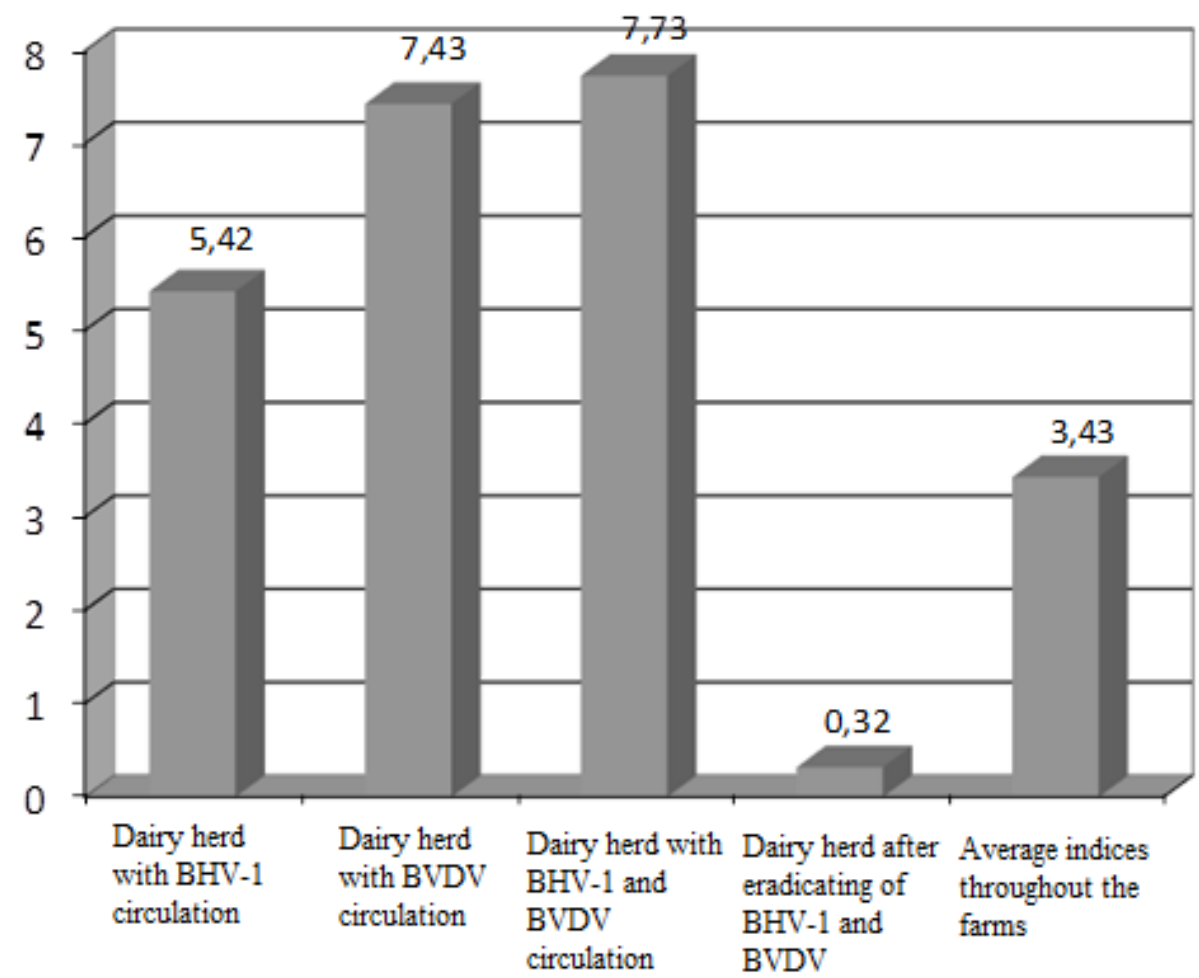

Fig.1. The rate of abortions in cows and heifers in dairy herds with different situations for the presence of viral infections, $\%$

While studying the level of distribution in dairy herds of cows of C. abortus, which is of great significance in the development of infections of the reproductive tract of cows and the occurrence of abortions, it was established that animals responded positively to ELISA in $41.3 \%$ of dairy herds. The number of seroprevalent to C. abortus animals on average in $2015-2019$ was $55.1 \%$, including $35.6 \%$ of cows, $16.3 \%$ of heifers, $3.2 \%$ of bred heifers. In PCR, 128 samples of biomaterial (cervical scrapings, vaginal swabs, organs of aborted fetuses) from animals of their disadvantaged farms were analyzed. DNa of C. abortus was detected in 8 samples of scrapings from the cervical canal $(6.25 \%)$ and 4 samples of organs from aborted fetuses $(3.12 \%)$, C. pecorum - in 1 sample of scrapings from the cervical canal $(0.78 \%)$.

The indices of total fertilization and fertilization from the first AI for the period 20152019 were less than in dairy herds with BVDV circulation, on average at the level of herds with BHV-1 circulation, and amounted to $73.0 \pm 2.6 \%$ and $43.0 \pm 3.4 \%$, respectively. The post-partum interval was on average 11-13 days longer. The rate of abortions in cows and heifers was $4.3 \%$, stillbirth rate was $13.5 \%$, and the number of pregnant animals fall out was $7.7 \%$. These indices are 1.3, 3.2, and 1.5 times higher than the regional average. If more than $50 \%$ of cows were identified as seropositive to C. abortus, the abortion rate was $7.4 \%$, and the number of stillborn calves was $19.1 \%$, which exceeds the average values for farms in the region by 1.7 and 4.3 times, respectively (Figure 2). Mean gestational age for abortions was $167.8 \pm 5.4$ days.

Indices on the prevalence of Neospora caninum, which is one of thereasons for abortions, among dairy farm animals were also studied. Among 112 studied samples, antibodies to N. caninum were recorded in $51(45.5 \%)$. On farms with detected seropositive animals, seroprevalence varies from $14.8 \%$ to $100.0 \%$, and averages $43.3 \%$. The abortion 
rate in epidemiologically disadvantaged herds was $5.7 \%$, and the stillbirth rate was $9.3 \%$, which is 2.5-3.2 times higher than the average for farms in the region.

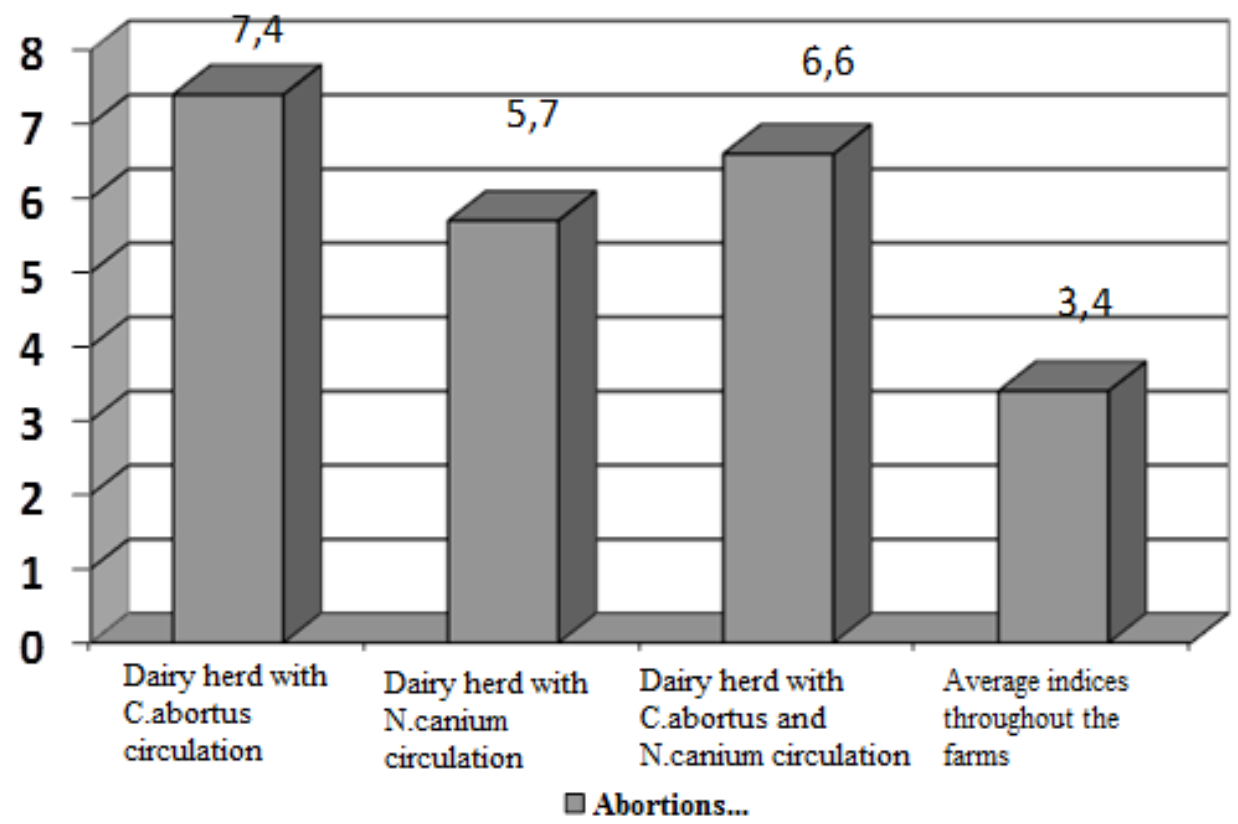

Fig.2. Reproductive losses in the dairy herds with dysfunctional epizootic situation for chlamydia and neosporosis

One of the farms in the Sverdlovsk region has been investigated for the occurrence of mass cases of prenatal losses. Out of 659 cows that were fertilized, during 2019, abortions were recorded in 63 animals, which amounted to an average of $9.6 \%$. However, the largest number of abortions $(n=50)$ was recorded in one of the farm's livestock facilities, which corresponded to $24.7 \%$ of the number of cows that were fertilized. The highest growth in the abortion rate was seen in May, followed by a decrease in cases in June-July and isolated cases in August-December. The average gestation period for abortions was 165.8 \pm 4.6 days. Meanwhile, at 90 to 140 days (first half of pregnancy), reproductive losses were recorded in 12 cows, and at 140 to 235 days (second half of pregnancy) in 51 cows, which accounted for $19 \%$ and $81 \%$ of the number of aborted animals, respectively.

Results of serological research revealed seroprevalence to $N$. caninum in $40.7 \%$ of the studied animals. Meanwhile, in the group of aborted cows studied, $100.0 \%$ of animals were seropositive, in the group of pregnant cows $-11.1 \%$. Further studies demonstrated that pregnancy in all animals of seconds group ended with the birth of viable calves. The average live weight of newborns was $39.4 \pm 0.8 \mathrm{~kg}$.

In dairy herds with a combination of infectious factors ( $N$. caninum $+C$. abortus), the average abortion rate for the study time was $6.6 \%$, and the stillbirth rate was $9.5 \%$.. Meanwhile, the herds were characterized by low rates of total fertilization and fertilization from the first insemination- $73.1 \pm 1.2 \%$ and $35.7 \pm 4.4 \%$, as well as a extended post-partum interval $-143.1 \pm 5.8$ days. This is mostly due to multiple inseminations of animals, which is caused by the development of inflammatory processes in the uterus.

We carried out a comparative analysis of indices of reproductive function in cows and heifers in farms with circulation of BHV-1, BVDV, C.abortus, N.caninum (Figure 3). 


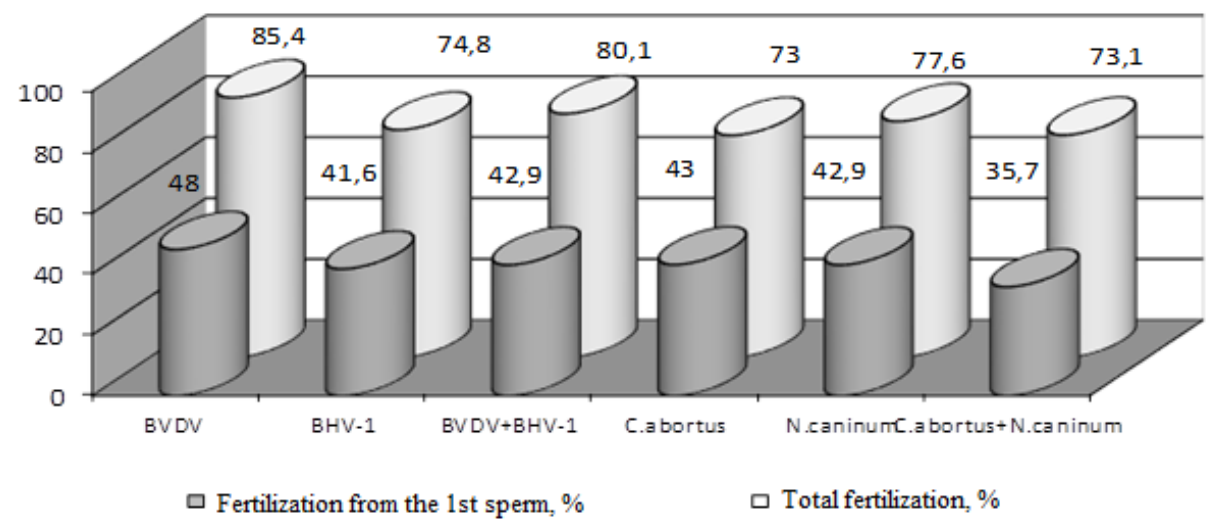

Fig.3. Indices of fertilization of cows during the circulation of viral, bacterial and protozoal infections in dairy herds

The lowest rates of total fertilization (73\%) and fertilization from the first AI (35.7$43.0 \%$ ) were found in farms with simultaneous circulation of chlamydia and neosporosis pathogens and in mono - chlamydia infection $(\mathrm{P} \leq 0.05)$. The same herds had a longer postpartum interval (138-143 days) $(\mathrm{P} \leq 0.01)$. In comparison of dairy herds with the circulation of viral infections in the conditions of their control with the use of specific immunoprophylaxis, it was determined that the greatest decline in indicators reflecting the ability of cows to fertilize is seen in the presence of BHV-1. The average post-partum interval was higher for mixed viral infection $(142.7$ days $)(\mathrm{P} \leq 0.01)$ owing to the circulation of pathogens of viral diarrhea and infectious bovine rhinotracheitis.

Findings of comparison of perinatal losses in cows and heifers depending on infectious factors are presented in the figure. The highest average rate of abortions in cows and heifers in 2015-2019 was in agricultural organizations with circulation of $N$. caninum $(7.8 \%)$ $(\mathrm{P} \leq 0.01)$, as well as mixed infections, with increased action of infectious factors $(6.6 \%$ $6.9 \%)(\mathrm{P} \leq 0,05)$. In the analysis of viral infections, it was found that the highest level of prenatal losses was seen in bovine viral diarrhea $(6.1 \%)$. The average stillbirth rate was higher for BVDV circulation (14.5\%) $(\mathrm{P} \leq 0.05)$, combined BVDV and $\mathrm{BHV}-1$ infection $(13.8 \%)(\mathrm{P} \leq 0.05)$, and Chl. abortus $(13.5 \%)(\mathrm{P} \leq 0.05)$.

Within the study period, 111 samples of biological materials (blood, placenta, fetus) from 101 aborted cows were also examined. BVDV antigens were found in $22.2 \%$ of the aborted animals studied. In $21.4 \%$ of the samples studied, $14.3 \%$ were found in the pathological material from aborted fetuses, $4.8 \%$ - in cervico-vaginal scrapings, and $2.4 \%$ in the blood serum of cows. Antibodies to C. abortus were identified in the blood serum of $54.6 \%$ of the studied animals. Antibodies to the agent of neosporosis were found in $44.4 \%$ of the aborted cows studied. Combined infection defined by the circulation of C. abortus and $N$. caninum pathogens was identified in $23.7 \%$ of the studied animals.

Serological studies confirmed the role of pathogens of viral, bacterial and protozoal infections in abortions in cows. At the same time, the main proportion in the structure of detected infectious agents during abortions is C. abortus and $N$. caninum $-45.1 \%$ and $36.6 \%$, respectively.

\section{Conclusiom}

The lowest rates of total fertilization (73\%) and fertilization from the first AI (35.7-43.0\%) were found on farms with simultaneous circulation of chlamydia and neosporosis pathogens 
and mono - chlamydia infection. In these same herds, the post-partum interval was longer (138-143 days). The comparison of dairy herds with the circulation of viral infections under vaccination conditions revealed that the greatest decrease in values reflecting the ability of cows to fertilize is observed in the presence of BHV-1. Mean period from birth to fertile insemination was higher for mixed viral infection (142.7 days) owing to the circulation of BVDV and BHV-1 pathogens.

The highest average rate of abortions in cows and heifers was in farms with $\mathrm{N}$. caninum circulation $(7.8 \%)$, as well as in mixed infections, with increased action of infectious factors $(6.6 \%-6.9 \%)$. The analysis of viral infections found that the highest level of prenatal losses was seen in BVDV (6.1\%). The average stillbirth rate was higher for BVDV circulation (14.5\%), combined BVDV and BHV-1 infection (13.8\%), and Chl. abortus $(13.5 \%)$.

Based on the findings of our research, it was determined that the greatest reproductive losses causing chlamydia and neosporosis in cattle, owing to their wide distribution and the complexity of controlling the epidemiological situation. Infections caused by BHV-1 and BVDV have less effect on the reproduction of animals in the herd, in connection with the vaccination of cows.

\section{References}

1. Christopher C.L. Chase, Robert W. Fulton, Donal O'Toole, Benjamin Gillette, Russell F. Daly, George Perry, Travis Clement. Vet Microbiol, 206, 69-77 (2017) DOI:10.1016/j.vetmic.2017.03.016.

2. F. Chike, Oguejiofor. Mechanisms linking bovine viral diarrhea virus (BVDV) infection with infertility in cattle, Cambridge University Press, 20 (1), $72-85$ (2019)

3. P. Vazquez. Veterinary research, 50 (1), 68 (2019)

4. C. M. Ribeiro, Ribeiro I. Soares, R.G. Mendes. Tropical animal health and production, 51(7), 1783-1800 (2019)

5. I.V. Vyalykh. Reproduction in Domestic Animals, 53 (2), 207 (2018)

6. A. Kierbic, M. Wieczorkiewicz, E. Zbikowska. Medycyna weterynaryjna-veterinary medicine-science and practice, 75 (7), 410-415 (2019)

7. Monika, Szymańska-Czerwińska \& Mitura. PLOS ONE, 12, e0174599 (2017) doi.10.1371/journal.pone.0174599.

8. S. Barati, Iran J Microbiol, 9 (5), 288-294 (2017)

9. Claire D. Wathes. Engineering, 6 (1), 26-33 (2020) 